\title{
Seasonal Variation of Microbial Activity and Pathogenic Bacteria under Non-serious Pollution Levels in Beijing
}

\author{
Sujian Zhang, Rui Du*, Hanlin Chen, Weishan Ren, Pengrui Du \\ College of Resources and Environment, University of Chinese Academy of Sciences, Beijing 100049, China
}

\begin{abstract}
Microbes are vital components of atmospheric fine particle matter $\left(\mathrm{PM}_{2.5}\right)$, and can have critical effects on human health (such as causing infectious diseases). Moreover, although China suffers from extensive concerns regarding human health issues related to air pollution, relatively few studies have focused on the characteristics of airborne microorganisms with respect to variations in air pollution, particularly under non-serious conditions. In this study, we used the modified fluorescein diacetate hydrolysis method to measure the seasonal microbial activity in $\mathrm{PM}_{2.5}$ during two levels of air pollution in Beijing. The mean microbial activity under excellent and good conditions (air quality index of $<100$ ) was distinctly higher than that under slight and moderate conditions (101-200) during all four seasons. We further explored relationships between microbial activity and bacterial species richness and community diversity. The relative abundance of pathogenic bacteria was quite low overall, being highest in autumn $(0.229 \%)$ and declining through winter $(0.207 \%)$, summer $(0.034 \%)$, and spring $(0.022 \%)$, the same pattern observed for microbial activity. However, there was no statistical difference in the relative seasonal abundance of pathogens. Of the six types identified, streptococcus was most prevalent $(0.23 \%)$. This study provides a reference and starting point for future research into the mostly unexplored field of pathogenic mechanisms during non-serious air pollution conditions.
\end{abstract}

Keywords: Microbial activity; FDA method; Pathogens; Pollution level.

\section{INTRODUCTION}

Over the past three decades, China has achieved great economic success, but has also encountered serious environmental problems. For example, air quality has deteriorated over most of the country since entering the new millennium due to haze, which occurs when particulate aerosols accumulate in the air and then scatter and absorb solar radiation, leading to atmospheric opacity and impairing visibility. Fine particulate matter (aerodynamic diameter $2.5 \mu \mathrm{m}, \mathrm{PM}_{2.5}$ ) is a critical component of haze pollution that affects air quality, regional climate, and human health and many studies have assessed the overall adverse health effects of exposure to $\mathrm{PM}_{2.5}$ (Duan et al., 2006; Franklin et al., 2007; Lang et al., 2017; Tarigan et al., 2017).

The occurrence frequency of so-called "haze episodes" in China has been decreasing since the government implemented the Air Pollution Prevention and Control Action Plan in 2013. Mass concentrations of $\mathrm{PM}_{2.5}$ have shown a steady decline along with improved air quality in

\footnotetext{
* Corresponding author.

Tel.: +86-10-69672840

E-mail address: ruidu@ucas.ac.cn
}

the Beijing-Tianjin-Hebei (BTH) region (Bi et al., 2019). For instance, rare blue sky appeared in Beijing during the 2014 APEC gathering, the so-called "APEC blue" event (Du et al., 2018a). In 2017, about 62.1\% percent of days reached an air quality index (AQI) of $<100$, an increase of 28 days compared with the previous year and 50 days more than in 2013. However, it has remained difficult for BTH to meet the World Health Organization's (WHO) recommended air quality standards for $\mathrm{PM}_{2.5}\left(10 \mu \mathrm{g} \mathrm{m}^{-3}\right.$ for annual mean and $25 \mathrm{\mu g} \mathrm{m}^{-3}$ for 24-hr mean) as the average annual concentration of $\mathrm{PM}_{2.5}$ is still more than $50 \mu \mathrm{g} \mathrm{m}{ }^{-3}$. During days exceeded air quality standards, $\mathrm{PM}_{2.5}$ was the primary pollutant $(54.3 \%$ in 2017$)$ (Beijing Environmental Statement, 2018).

Under these conditions, non-serious air pollution conditions have become the ordinary condition. Although extensive studies have focused on $\mathrm{PM}_{2.5}$ under serious pollution conditions (Chan and Yao, 2008; Cao et al., 2014; Li et al., 2015; Dong et al., 2016; Wei et al., 2016; Zhang et al., 2016; Gao et al., 2017a; Xu et al., 2017), fewer have considered the influence of $\mathrm{PM}_{2.5}$ on human health under non-serious air pollution levels (AQI < 200) despite the risks to human health posed by long-term exposure to these conditions. For example, Shi et al. (2016) suggested that both short- and long-term exposure to $\mathrm{PM}_{2.5}$ were associated with all-cause mortality, even for exposure 
levels under $10 \mu \mathrm{g} \mathrm{m}^{-3}$.

Most current research has focused on the chemical composition and size distribution of $\mathrm{PM}_{2.5}$ in urban areas (Li et al., 2011; Xiu et al., 2015; Dong et al., 2016; Zhao et al., 2016; Zhang et al., 2016). However, biological materials account for $25 \%$ (by mass) of total airborne particles, including bacteria, fungi, and microbial fragments ranging in size from nanometers to millimeters (Jones and Harrison, 2004; Jaenicke, 2005; Smets et al., 2016). Certain pathogens that attach to $\mathrm{PM}_{2.5}$ can trigger human health problems including allergies, inflammation, and infections (Whyte et al., 1982; Polymenakou, 2012). Fan et al. (2019) detected more pathogenic bacteria in $\mathrm{PM}_{2.5}$ than $\mathrm{PM}_{10}$. However, the potential risks associated with various characteristics of bioaerosols (such as community structure, diversity, relative abundance, dynamics, and nosogenesis) have yet to be fully studied.

Many recent studies have considered biological components in $\mathrm{PM}_{2.5}$, especially during high-pollution periods (Li et al., 2011; Qi et al., 2015; Dong et al., 2016; Gao et al., 2016; Meng et al., 2016; Xie et al., 2018; Fan et al., 2019). For example, Cao et al. (2014) used advanced metagenomic sequencing to show that bacteria related to $\mathrm{PM}_{2.5}$ constituted $80 \%$ of total airborne microbes in the lower atmosphere and inhalable particles contained higher levels of allergenic and pathogenic materials during the famous Beijing severe-haze episode in January 2013. Guan et al. (2014) detected airborne endotoxins in $\mathrm{PM}_{2.5}$ and found that their concentrations were associated with chemical compositions and positively correlated with reactive oxygen species (ROSs). Wei et al. (2016) used an ultraviolet aerodynamic particle spectrometer to monitor the dynamics of bioaerosol variation on both hazy and sunny days in Beijing from December 2013 to March 2014. They found that biological particle size skewed toward $<1 \mu \mathrm{m}$ on hazy days in contrast to a fairly normal distribution with a peak around $2 \mu \mathrm{m}$ on sunny days. Moreover, they showed that the highest concentrations of biological particulate matter were associated with higher AQI values (> 300) and suggested that major fine particulates could be dominated by biological matter under hazy conditions.

Gao et al. (2015) used an Andersen six-stage impactor to sample culturable bioaerosols during different seasons and haze events in Beijing from January 2013 to January 2014, finding that the concentration of culturable airborne bacteria decreased with heavier air pollution and the concentration proportion of larger-diameter bioaerosols increased on hazier days. They also analyzed the effect of environmental factors on the concentration and diameter of culturable bioaerosols and attributed seasonal variations in the former (but not the latter) to the effect of $\mathrm{PM}_{2.5}$. Li et al. (2015) observed that the concentrations of viable bacteria and fungi during hazy days were clearly higher than during non-hazy days and that more allergic and infectious genera were detected during the former in Xi'an, China.

Culture-based methods are limited by the fact that culturable microbes account for $<5 \%$ of total airborne microorganisms (Després et al., 2012) and metagenomic sequencing has not been widely used due to its cost. Thus, the high throughput sequencing method (another DNAbased method) has been commonly used to investigate microbial communities (Gao et al., 2017b). For example, Du et al. $(2018 \mathrm{~b}, \mathrm{c})$ using two years of $\mathrm{PM}_{2.5}$ data showed significant seasonal differences in bacterial species richness, community diversity, and structure in urban Beijing, in contrast to no significant seasonal differences in suburban Beijing except for community structure. For the whole year, there was no obvious relationship between air pollution levels and bacterial species richness or community diversity in either urban or suburban Beijing. At a seasonal scale, bacterial species richness and community diversity decreased with increasing air pollution levels, precipitation variations had no significant impact. In contrast, changes in these indicators for fungi were much more complicated and irregular.

Similarly, Xu et al. (2017) characterized the bacterial populations of ultrafine particles $\left(\mathrm{PM}_{0.18-0.32}, \mathrm{PM}_{0.32-0.56}\right.$, and $\left.\mathrm{PM}_{0.56-1}\right)$ under severe haze episodes using highthroughput sequencing and real-time quantitative PCR detection based on 21 samples collected from January to March 2014 in Ji'nan, the capital of Shandong Province in the central North China Plain. Their results found high bacterial concentrations and community diversity, including some infectious and allergenic species in submicron particles during haze episodes; the bacterial community varied significantly in different size fractions. However, their study did not contrast these results with those for non-haze conditions. Li et al. (2017) determined the characteristics of viable bacterial and fungal aerosols under different weather conditions using an Andersen six-stage sampler in Xi'an, a typical semi-arid city of Northwest China. Their results indicated that the bacterial size spectrum had a tendency to move slightly toward fine particles during haze events and mean concentrations of viable bioaerosols on hazy days were much higher than on non-hazy days, in contrast to Gao et al. (2015)'s results in Beijing.

Overall, research on bioaerosol characteristics in China has considered concentration levels, size distributions, community structure, and composition over different sampling regions, sampling periods, and analysis methods, but no standardized sampling protocols have been established and there is a dearth of systematic and consistent results. Additionally, it has been difficult to monitor the real-time biological activity status of airborne biological agents due to current technological limitations. Moreover, most current methods are incapable of indicating intensity of active biomass in $\mathrm{PM}_{2.5}$, whereas, fluorescein diacetate (FDA) hydrolysis can measure enzyme activity in airborne microbes (Green et al., 2006; Qi et al., 2015). The amount of microbial activity can reflect the relative activity of metabolic and other basic physiological processes and is a vital indicator of microbial properties and their influence in atmospheric bioaerosols (Meng et al., 2016). Additionally, there is yet a clear need for further research on pollution mechanisms and necessary control measures in order to reduce atmospheric concentrations of $\mathrm{PM}_{2.5}$ (and associated bioaerosols) and improve air quality in the near and long term. In this study, we collected samples of $\mathrm{PM}_{2.5}$ from suburban Beijing for 
two years to determine the relationship between microbial activity and indices such as pathogenic bacteria, community diversity, and species richness under non-serious pollution levels in different seasons. This approach was intended to better elucidate the nosogenesis of adverse health effects during low-level $\mathrm{PM}_{2.5}$ exposures in order to guide the development of suitable environmental standards and mitigate further exposure risks in China.

\section{METHODS}

\section{Sampling Site and AQI}

All samples were collected from the rooftop of the Teaching-one Building ( $30 \mathrm{~m}$ elevation) located on the Huairou campus of the University of Chinese Academy of Sciences $\left(40^{\circ} 24^{\prime} 29^{\prime \prime} \mathrm{N}, 116^{\circ} 40^{\prime} 28^{\prime \prime} \mathrm{E}\right)$ in a peri-urban village in the northeastern Huairou district, Beijing. This location has a lake $\left(230 \mathrm{~km}^{2}\right)$ on its southwestern side, vegetated mountains $\left(1.5 \mathrm{~km}^{2}\right)$ to the west and north, and a national road $\sim 200 \mathrm{~m}$ to the east. No nearby industrial manufacturing pollution sources directly affect the sampling site. The area surrounding the sampling site is positioned as an ecological development demonstration zone in Beijing. The climate is temperate (average temperate $9-13^{\circ} \mathrm{C}$ ) and semi-humid with four distinct seasons; peak heat and precipitation coincide during the humid summer while winter is cold with snow. The average annual precipitation is $600-700$ $\mathrm{mm}$, mainly occurring during from June to August.

AQI values determined by the China Meteorological Administration (CMA) were acquired from the Beijing Municipal Ecological Environment Bureau (http://sthjj.beijing.gov.cn/). The Technical Regulation on Ambient Air Quality Index (on trial) divides AQI into six levels: excellent $(0-50)$, good $(51-100)$, slight pollution (101-150), moderate pollution (151-200), heavy pollution (201-300), and severe pollution ( $>300)$. We defined days with AQI $<200$ as non-serious pollution days $(93.7 \%$ of days in 2017) and divided them into two levels: excellent and good (0-100) and slight and moderate (101-200).

\section{Sample Collection for Microbial Activity in $\mathrm{PM}_{2.5}$}

$\mathrm{PM}_{2.5}$ samples were collected on quartz membranes sterilized by baking in a Muffle furnace at $550^{\circ} \mathrm{C}$ for $5 \mathrm{~h}$. We used an OMNI FTTM Ambient Air Sampler with a flow rate of $5 \mathrm{~L} \mathrm{~min}^{-1}$ for $40 \mathrm{~min}$ (08:00 to 08:40 China Standard Time) to minimize the effect of the instruments on microbial activity; the observation period ran from May 2017 to April 2018. As our focus was on the properties of microbial activity in $\mathrm{PM}_{2.5}$ under non-serious pollution levels, we selected 100 samples from days meeting those conditions. We further assessed seasonal variation during spring (18 samples), summer (13), autumn (45), and winter (24); these divisions were not equal due to differing atmospheric conditions and sample availability.

The microbial activity of bioaerosols in $\mathrm{PM}_{2.5}$ was determined by the modified FDA hydrolysis method documented by Ren et al. (2018). Membranes containing bioaerosol samples were cut into 8 pieces for parallel measurements and put into a $10 \mathrm{~mL}$ centrifuge tube with
$5 \mathrm{~mL}$ physiological saline. One piece of blank quartz membrane was processed identically at the same time. The centrifuge tube was shaken at $30^{\circ} \mathrm{C}$ for $30 \mathrm{~min}$ at a rotation of $150 \mathrm{r} \mathrm{min}^{-1}$. Next, $50 \mu \mathrm{L}$ of $200 \mu \mathrm{g} \mathrm{mL} \mathrm{m}^{-1}$ FDA solution was used to start the reaction and the tube was held at $30^{\circ} \mathrm{C}$ for $90 \mathrm{~min}$ in the dark. After $5 \mathrm{~mL}$ acetone was added to terminate the reaction, $15 \mathrm{~min}$ later the tube was centrifuged at a rate of $10,000 \mathrm{rmin}^{-1}$ for $1 \mathrm{~min}$. Finally, the relative fluorescence intensity of the supernatant taken from the tube was measured by a Spectra Max Paradigm Multi-Mode detection platform $\left(\lambda_{\mathrm{ex}}=490 \mathrm{~nm}, \lambda_{\mathrm{em}}=530 \mathrm{~nm}\right)$. All operations were performed under sterile conditions.

\section{Sample Collection for Sequencing Analysis}

Further $\mathrm{PM}_{2.5}$ samples were obtained on $150 \mathrm{~mm}$ quartz membranes (Whatman ${ }^{\mathrm{TM}}$, GE Healthcare, USA) treated as above. Sampling was conducted for $23 \mathrm{~h} 50 \mathrm{~min}$ (08:00 to 07:50 next day, China Standard Time) at a flow rate of $0.5 \mathrm{~m}^{3} \mathrm{~min}^{-1}$ using a high-volume air particulate matter sampler (DHA-80, Digital, Switzerland); the observation period in this case ran from September 2015 to October 2016. As above, we selected samples representing non-serious pollution days (93 total), and assessed these for seasonal variation during spring (28 samples), summer (16), autumn (26), and winter (23). These samples were stored at $-80^{\circ} \mathrm{C}$ for further analysis.

\section{DNA Extraction and PCR Amplification}

The samples from different seasons were sorted into two groups: Group1 (AQI < 100) and Group2 $(101<\mathrm{AQI}<$ 200). In order to guarantee the representativeness of the subsequent experiments, we cut off an equal area of each quartz membrane and gathered the fractions to ensure that the gross membrane size for different air pollution levels in different seasons was equal to $30 \mathrm{~cm}^{2}$.

Microbial DNA was extracted using a PowerSoil DNA isolation kit (MoBio Laboratories, Carlsbad, CA, USA) according to the manufacturer's protocols. Extracted DNA samples were stored at $-80^{\circ} \mathrm{C}$ until further analysis. The V3-V4 region of $16 \mathrm{~S}$ rRNA was amplified using a bacterial universal PCR primer set $338 \mathrm{~F} \quad\left(5^{\prime}-\right.$ ACTCCTACGGGAGGCAGCA-3') and 806R (5'GGACTACHVGGGTWTCTAAT-3'). PCR amplification was performed in a $25 \mu \mathrm{L}$ reaction mixture containing $0.2 \mathrm{mM}$ dNTPs, $0.2 \mu \mathrm{M}$ primer, $1 \times$ PCR buffer, 0.6 Units taq DNA polymerase, and approximately $10 \mathrm{ng}$ template DNA. PCR was performed in the following sequence of conditions: $94^{\circ} \mathrm{C}$ for $5 \mathrm{~min} ; 30$ cycles of $94^{\circ} \mathrm{C}$ for $5 \mathrm{~s}$, $50^{\circ} \mathrm{C}$ for $30 \mathrm{~s}$, and $72^{\circ} \mathrm{C}$ for $45 \mathrm{~s} ; 72^{\circ} \mathrm{C}$ for $5 \mathrm{~min}$; then held at $4{ }^{\circ} \mathrm{C}$. The final products were separated by $1 \%$ agarose gel electrophoresis and purified using an Axygen nucleic acid purification kit (Axygen, Biosciences, CA, USA). The purified PCR products were prepared for sequencing using on the Illumina MiSeq PE300 platform (Illumina, San Diego, CA, USA) by the Majorbio company (Shanghai, China).

\section{Sequence Analysis}

The $16 \mathrm{~S}$ gene sequences were processed and analyzed using the open-source software package Mothur. Analysis 
sequences shorter than $400 \mathrm{bp}$, longer than $470 \mathrm{bp}$, with homopolymer stretches of more than $8 \mathrm{bp}$, or containing ambiguous bases were removed. After quality control, the species richness index (Chao1), coverage, diversity index (Shannon), and relative abundance were calculated by a series of processing protocols documented in Du et al. (2018c). PCR chimeras were identified using chimera.uchime. Subsequent processing was performed as described in Kozich et al. (2013). Sequences were clustered into operational taxonomic units (OTUs) by setting a distance of 0.03 . The bacterial sequences were assigned to phylotypes using a Bayesian approach against the Ribosomal Database Project 16S rRNA gene training database with a confidence threshold of $70 \%$ (Wang et al., 2007). Raw sequencing data were deposited to the NCBI Sequence Read Archive under accession number SRR5440000.

\section{RESULTS AND DISCUSSION}

\section{Seasonal Variation in Microbial Activity in $P_{2.5}$ Associated with AQI}

In general, when AQI increased notably, the microbial activity in $\mathrm{PM}_{2.5}$ descended significantly (Fig. 1). For example, in spring, AQI increased gradually from March 20 to 23 while microbial activity decreased from 0.84 to $0.17 \mathrm{ng} \mathrm{m}^{-3}$; when AQI peaked near 150, as on March 12, 18, 23, 29, and April 1, microbial activity dropped below
$0.3 \mathrm{ng} \mathrm{m}^{-3}$ (Fig. 1(a)). In summer, AQI increased from July 16 to July 19 while microbial activity simultaneously declined (Fig. 1(b)). In autumn, AQI peaked near 200 on October 27 and October 6, while microbial activity on these two days ( 0.63 and $0.24 \mathrm{ng} \mathrm{m}^{-3}$, respectively) was near the minimum value (Fig. 1(c)). In winter, the highest AQI (December 29) correlated with the lowest microbial activity $\left(0.10 \mathrm{ng} \mathrm{m}^{-3}\right)$ (Fig. 1(d)).

However, this negative correlation between microbial activity and AQI was not universal. For example, on December 4 and 23, both recorded very low values and similar patterns occurred in the other seasons. This may relate to complicated, poorly understood cause-and-effect mechanisms operating between meteorological factors and chemical compositions. For example, air quality might improve following strong winds or precipitation that could also temporarily cleanse the air of microbes, resulting in excellent air quality with a lag effect of low microbial activity. Such fluctuations were observed by Wei et al. (2016) over 12 consecutive days in Beijing during which the particle concentration increased and then decreased as the haze $(\mathrm{AQI}>150)$ was in progress.

Overall, deterioration of air quality during non-serious pollution conditions tended to correlate with lower microbial activity in $\mathrm{PM}_{2.5}$ in all seasons, though no specific or complete framework for this pattern could be determined. This result was consistent with Gao et al. (2015), who
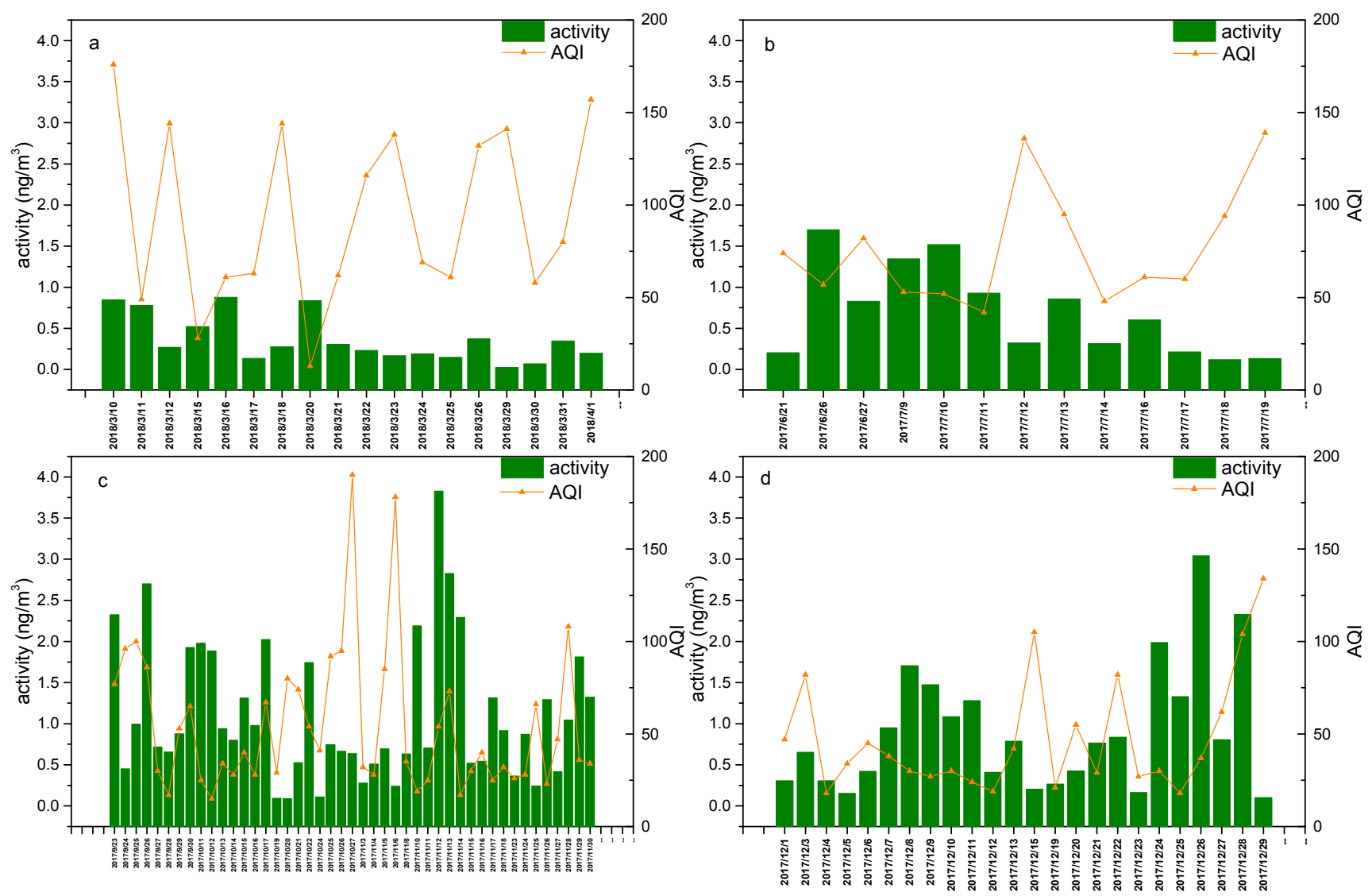

Fig. 1. Comparison of microbial activity (concentration of sodium fluorescein) in $\mathrm{PM}_{2.5}$ and AQI during (a) spring, (b) summer, (c) autumn, and (d) winter. 
observed culturable airborne bacteria in Beijing during four seasons at four haze levels and determined that the concentration of culturable airborne bacteria decreased as air pollution increased; they also suggested that haze had a deleterious influence on these bacteria.

Seasonal average microbial activity was highest in autumn (1.11 ng m $\left.\mathrm{m}^{-3}\right)$, decreasing through winter $\left(0.91 \mathrm{ng} \mathrm{m}^{-3}\right)$, summer $\left(0.70 \mathrm{ng} \mathrm{m}^{-3}\right)$, and spring $\left(0.37 \mathrm{ng} \mathrm{m}^{-3}\right)$, with an overall average for all four seasons of $0.88 \mathrm{ng} \mathrm{m}^{-3}$ (Fig. 2). Zhong et al. (2016) used similar methods to measure microbial activity in bioaerosol particles collected by sixstage Andersen impactors in the Chinese coastal region of Qingdao. However, they found average microbial activity ranging from $5.59-102 \mathrm{ng} \mathrm{m}^{-3}$ (average $34.4 \mathrm{ng} \mathrm{m}^{-3}$ ) quite different from our results. The much lower microbial activity in Beijing than in Qingdao may relate to different populations of terrestrial and marine microbes. For example, Zhong et al. (2016) collected a far larger size range of bioaerosol particles $(0.65-7.0$ and $>7 \mu \mathrm{m})$ than in our study $(<2.5 \mu \mathrm{m})$, which may explain the discrepancy (along with differences in the sampling particulate size range and air flow).

Furthermore, the effects of environmental factors such as source and meteorological factors such as temperature on microbial activity are unclear. For example, different sources of bioaerosols can result in different abundances (Christner et al., 2008; Kurkela, 1997). Moreover, Li et al. (2013) found that bacterial community structures varied with different geographical locations, based on air samples collected from automobile air conditioning systems in Beijing. Additionally, the influence of bacterial species richness and community diversity should not be ignored.

The high values in autumn may be explained by multiple local factors. First, the autumn temperature range in Beijing $\left(15-25^{\circ} \mathrm{C}\right)$ is suitable for microbes to metabolize and perform other physiological activities, while temperatures beyond this range may have inhibitory effects (Slonczewski and Foster, 2013). Moreover, sandstorms with strong winds carrying sand and soil occur frequently in Beijing in autumn; these can increase the concentrations of both culturable microbes and total microbes in bioaerosols ( $\mathrm{Li}$ et al., 2011). Leaves are another important source of bioaerosols; these begin to fall in autumn in Beijing, when a huge number of biological particles are aerosolized by winds that also transport adequate nutrients supporting microbial growth and reproduction.

During winter, the sharply declining temperature results in slower enzymatic processes. Moreover, the non-serious air pollution days we observed might have been accompanied by strong winds or precipitation that could partially remove active microbes, but, the occurrence frequency of above weather is relative lower, resulting in winter levels lower than autumn but still higher than spring and summer. In addition, during Beijing winters, variations in ground heat radiation often result in the formation of thermal inversion layers in the troposphere. The resulting stable meteorological conditions could prevent particulate matter and pollutants from dispersing, leading to microbial accumulation.

The low microbial activity in spring may relate to the relatively low average temperature along with the sharp day/night changes in temperature typical of the area, as large fluctuations in daily temperature are not suitable for microbial growth. Additionally, average spring wind speed ranges from approximately level II to level IV and gustiness is frequent, bringing clean air to the region and removing airborne microorganisms. In summer, high solar radiation intensity has a significant negative influence on the culturability of airborne microorganisms (Tang, 2009). In addition, frequent rainfall in summer can also wash away large amounts of airborne microbes and decrease microbial activity.

Zhong et al. (2016) reported that microbial activity in Qingdao varied seasonally from summer $>$ autumn $>$ winter $>$ spring, with different sampling sites and meteorological

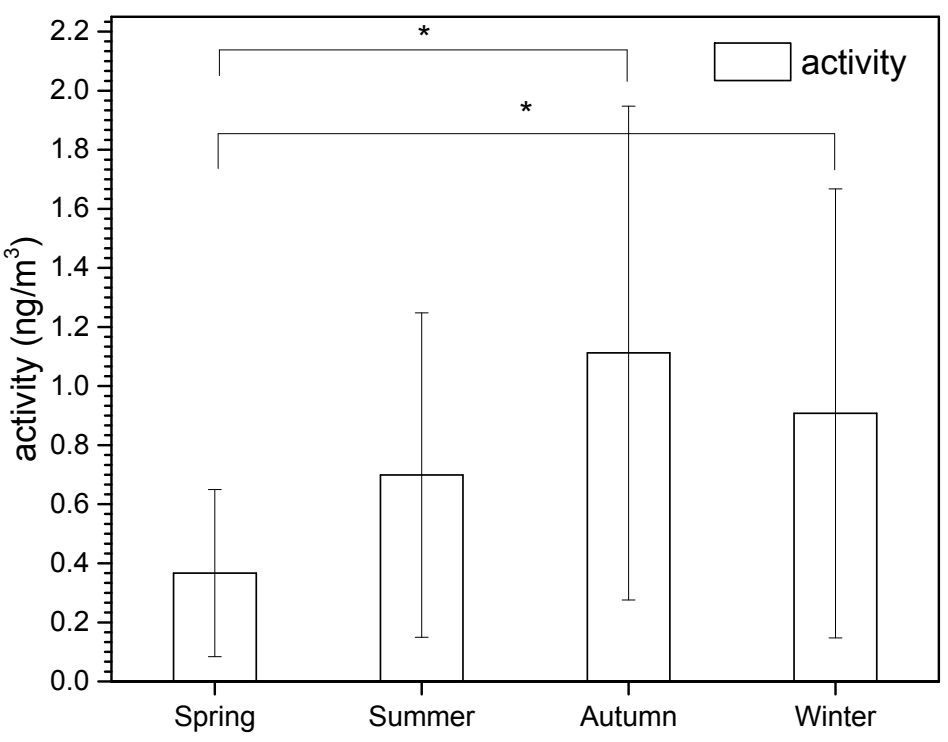

Fig. 2. Seasonal microbial activity (concentration of sodium fluorescein) under non-serious air pollution levels $(A Q I<$ 200). 
factors. In other words, in Qingdao the maximum microbial activity occurred in summer, but in Beijing microbial activity in summer was only the third-highest of all seasons. In Qingdao, the average summer temperature $\left(23.7^{\circ} \mathrm{C}\right)$ was suitable for microbial growth and frequent foggy days could protect microbes from damage caused by the solar radiation. In contrast, Beijing summers have many sunny days with high solar radiation that inhibits the growth of microbes, while frequent rainfall cleanses the air. Moreover, in summer the prevailing southeastern wind in Qingdao carry marine microbes into that coastal city. Zhong et al. (2016) also found no statistical correlation between microbial activity and total airborne microbes (TAMs), but did not suggest reasons for this due to a lack of research on this subject. Thus, many possible explanations for variations in microbial activity and total microbial concentration remain to be explored.

The average microbial activity under excellent and good $(\mathrm{AQI}<100)$ conditions was distinctly higher than under slight and moderate conditions (AQI 101-200) during all four seasons, although no statistical differences were observed (Fig. 3). In contrast, Xie et al. (2018) assessed total airborne microbes (TAMs) under various air quality levels in Xi'an from April 2016 to February 2017, finding that the concentration of TAMs on hazy days (AQI $>100)$ was notably higher than on non-hazy days (AQI $<100)$.

As we limited our study to conditions of AQI $<200$, our results naturally reflected a different range than studies without such a limit, which could partially account for differing results between this and previous studies. In general, it seems clear that microbial activity was affected by the air pollution levels. Although we suggested that microbial activity should decrease with air pollution levels increasing, the intensity of microbial activity in autumn and winter was higher than in spring and summer. The frequent foggy and hazy days in autumn and winter could increase the quantity of microbes and hinder the harm effects of ultraviolet rays, while the more stable atmosphere could likewise lead to microbial accumulation.

\section{Correlation between Bacterial Species Richness and Community Diversity and Microbial Activity}

Few studies have focused on factors associated with microbial activity. Zhong et al. (2016) investigated the influences of meteorological factors on bioaerosols and suggested that temperature and wind speed had significant correlations with microbial activity. We assumed that bacterial species richness and community diversity might have specific influences on microbial activity, using the Chaol index to assess species richness (overall number) and the Shannon index to assess community diversity (number and distribution of species in different groups). Biological particulate matter is a complex combination of bacteria, spores from fungi, moss, and ferns, pollen, plant fibers, and animal debris (Lacey and Dutkiewicz, 1994). We integrated the two-year observed data due to an absence of concurrent observation data. There was no statistical correlation between microbial activity and community diversity or species richness for either AQI category (Fig. 4).

Under excellent and good conditions (Fig. 4(a)), microbial activity was lowest in spring but peaked in autumn, while both indices peaked in spring but were lowest in summer. Microbial activity increased with the decline of species richness and community diversity from spring to summer, then continued to increase as species richness and community diversity rose from summer to autumn.

Under slight and moderate conditions (Fig. 4(b)), both indices and microbial activity were lowest in summer, possibly due to high temperatures (up to $40^{\circ} \mathrm{C}$ in Beijing) and intense solar radiation as discussed above. Mutualism and/or competition between species may have resulted in some variation in microbial activity. Microbial activity increased along with species richness from summer to winter; while an increase in the number of species might

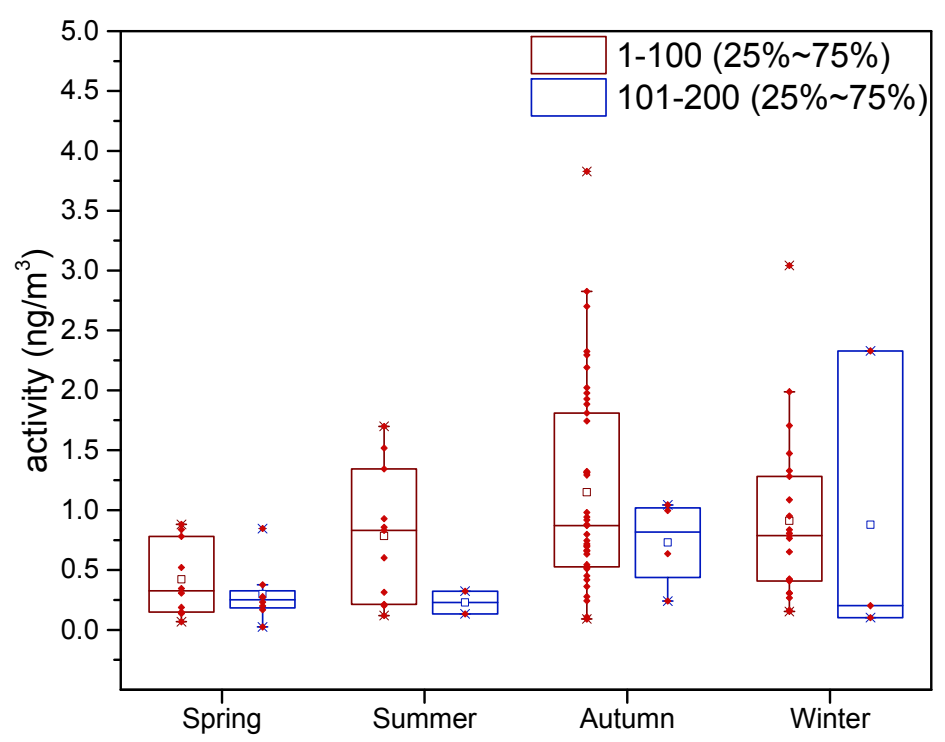

Fig. 3. Seasonal microbial activity at two AQI levels (1-100 and 101-200). Red points represent the sample size for each group, squares mark mean values. 


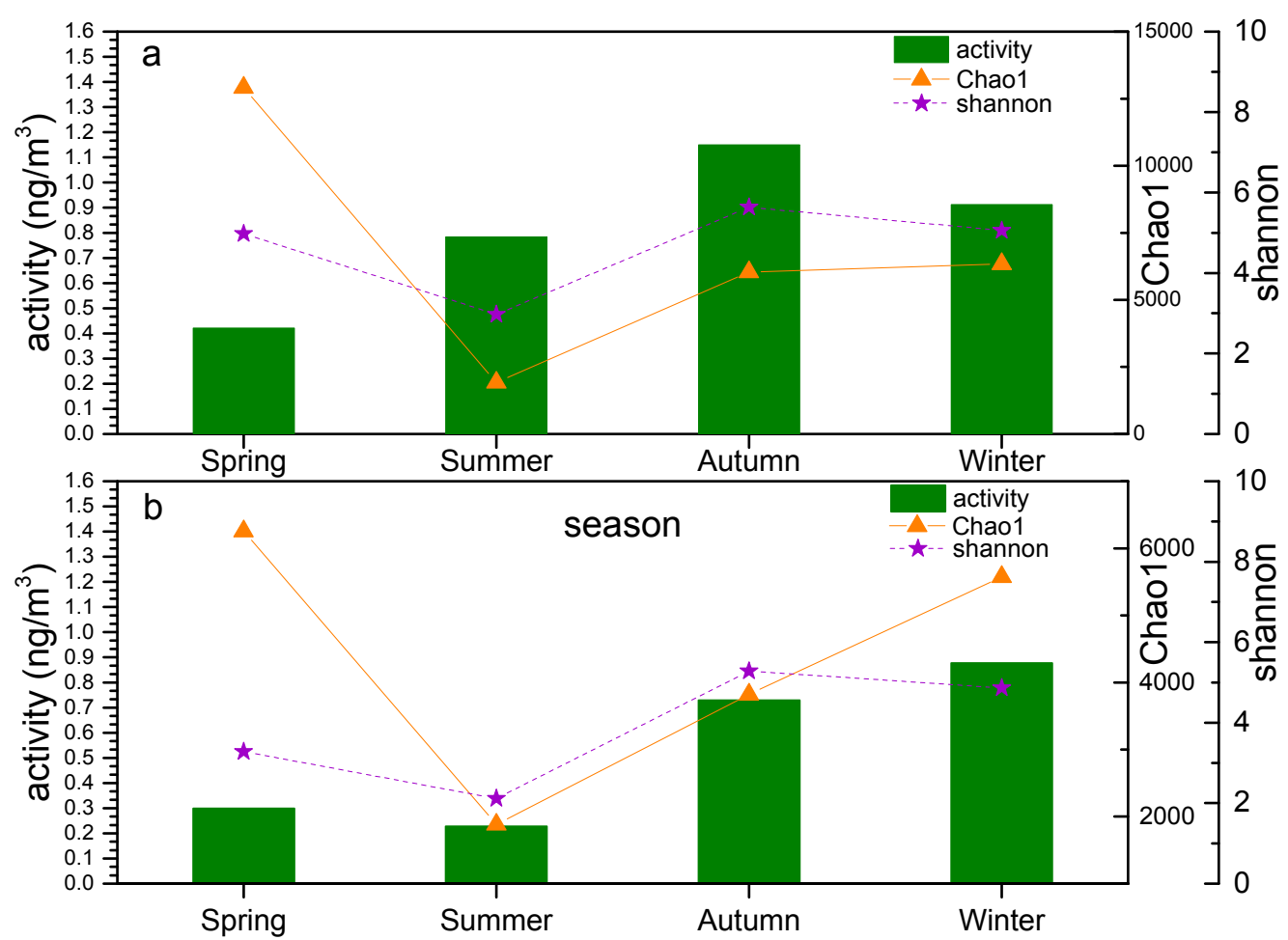

Fig. 4. Effect of bacterial species richness (Chaol index) and community diversity (Shannon index) on microbial activity in $\mathrm{PM}_{2.5}$ under (a) excellent and good (AQI 1-100) and (b) slight and moderate (AQI 101-200) conditions. Bars represent average microbial activity.

improve the intensity of microbial activity, we cannot be certain as the observation periods were not synchronized. Furthermore, previous research showed that the highest species richness and community diversity in spring decreased with worse air pollution (Du et al., 2018b), although no explanation was available for this phenomenon. In this study, we showed that microbial activity decreased as air quality deteriorated, meaning that community diversity and species richness might have uncertain direct influences on microbial activity, which should be studied further.

\section{Variation in Pathogenic Bacteria in PM $\mathbf{P}_{2.5}$}

We obtained $\sim 281,456$ sequences of the bacterial $16 \mathrm{~S}$ rRNA gene after excluding non-qualified gene sequences and chimeric sequences in the $\mathrm{PM}_{2.5}$ samples, with 91$99 \%$ coverage of the gene sequences. Through querying and comparing the directory of pathogenic microorganism infecting humans promulgated by the Ministry of Health of the People's Republic of China (MOHC), six kinds of pathogenic bacteria (Rickettsia, Erysipelothrix, Prevotella, Streptococcus, Shigella, and Brucella) were identified in $\mathrm{PM}_{2.5}$, though sequences of pathogenic bacteria in $\mathrm{PM}_{2.5}$ were scarce and accounted for $<1 \%$ overall (Fig. 5(a)).

The seasonal abundance of pathogenic bacteria was highest in autumn $(0.229 \%)$, followed by winter $(0.207 \%)$, summer (0.034\%), and spring (0.022\%) (Fig. 5(b)), a trend similar to that of microbial activity. $\mathrm{PM}_{2.5}$ harbored more pathogenic bacteria in autumn, with a higher metabolic activity, than in any other seasons. However, there were no significant differences in pathogenic bacteria between seasons. Streptococcus, which can cause diseases such as wound infection and pink eye, was the most abundant (0.23\%). Abd Aziz et al. (2018) collected $\mathrm{PM}_{2.5}$ samples using a high-volume air sampler at an average flow rate of $1130 \mathrm{~L} \mathrm{~min}^{-1}$ for $24 \mathrm{~h}$ per day in southern South Korea, finding 19 kinds of opportunistic pathogenic bacteria genera related to humans, plants, and food, including Streptotococcus, Bacillus, and Pseudomonas. Li et al. (2013) found that air samples collected from the automobile air conditioning systems in Beijing contained $>400$ unique bacteria including human pathogens and pathogenic fungal species.

The relative abundance of pathogenic bacteria was lower when air quality was poorer in both spring and autumn, but the opposite occurred in summer and winter (Fig. 5(b)). The relative abundance of pathogenic bacteria was significantly higher in autumn and winter than in spring and summer. Our observations of microbial activity of $\mathrm{PM}_{2.5}$ also showed levels in autumn and winter than in spring and summer. Bacteria-producing beta-lactamases could cause direct infections or have indirect effects through their ability to produce these enzymes (Brook, 2009). As microbial activity was an indicator of enzyme activity in this study, there may be a correlation between the relative abundance of pathogenic bacteria and microbial activity.

Additionally, there was no significant difference of the relative abundance of pathogenic bacteria between the two pollution levels. Thus, the deleterious influence of pathogenic bacteria under non-serious conditions should attract more public attention and further research is needed to estimate 


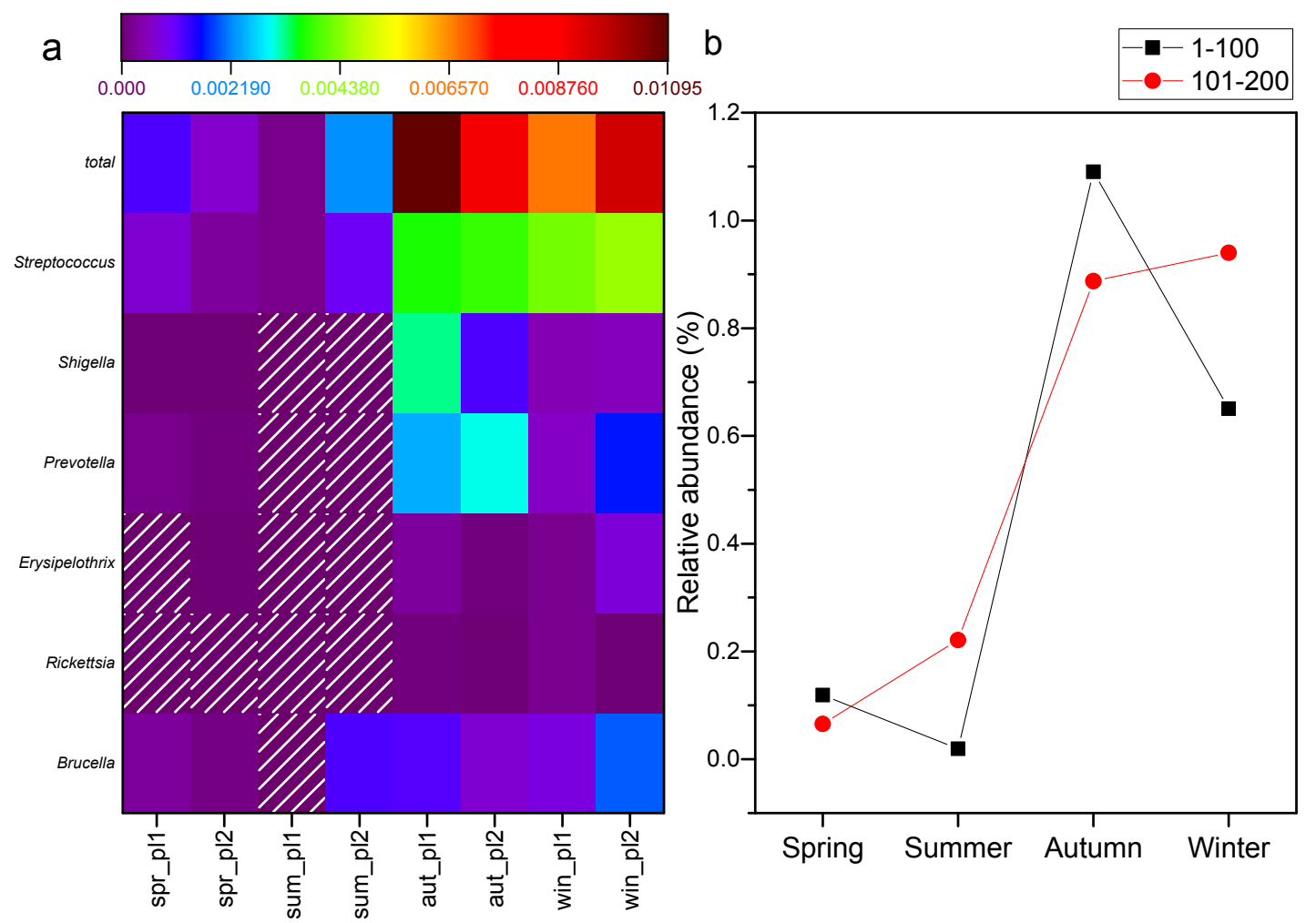

Fig. 5. (a) Heat map of relative abundance of pathogenic bacteria in different samples. White-lined squares represent values of 0 . (b) Seasonal variation in relative abundance of pathogenic bacteria under different air pollution levels.

potential health effects. Cao et al. (2014) suggested that the relative abundance of several respiratory allergens and pathogens appeared to increase with increasing PM concentrations on hazy days, which might affect their influence on the environment and human health. Fan et al. (2019) also showed that significantly more opportunistic pathogenic bacteria were found in winter than in autumn, and more opportunistic pathogenic bacteria were found in $\mathrm{PM}_{2.5}$ than in $\mathrm{PM}_{10}$.

Although higher mortality is closely related to the effects of serious urban air pollution (Xu et al., 2013; Fan et al., 2019), long-term exposure to non-serious air pollution levels may also have adverse health effects. However, few studies have considered pathogenic exposure under nonserious air pollution levels, meaning that the health risks may be overlooked by current Chinese environmental public health policies. Overall, we suggest that the distribution of airborne microbial components (especially pathogenic flora and microbial activity) in atmospheric $\mathrm{PM}_{2.5}$ should be further studied to reveal the adverse health effects of exposure during low concentrations of $\mathrm{PM}_{2.5}$.

\section{CONCLUSIONS}

We investigated airborne microbial characteristics using the modified fluorescein diacetate (FDA) hydrolysis method under non-serious air pollution conditions (AQI < 200) that have been mostly overlooked by previous research. Microbial activity was highest in autumn, followed by winter, summer, and spring. In general, when the AQI increased notably, the microbial activity in $\mathrm{PM}_{2.5}$ decreased significantly. The mean value of microbial activity under excellent and good conditions (AQI < 100) was distinctly higher than that under slight and moderate conditions (AQI 101-200) during all four seasons. In contrast, there was no statistically relevant connection between microbial activity and species richness or community diversity. The relative abundance of pathogenic bacteria followed the same seasonal pattern as microbial activity; Streptococcus was the most common at $0.23 \%$.

Our results suggest that policy makers and the general public should pay more attention to health risks during non-serious air pollution conditions, which have otherwise been ignored in comparison with severe haze conditions in China. Long-term exposure to non-serious air pollution levels can also have potential detrimental influences on human health. Although the fact that our two sampling periods were not concurrent limits the full value of the results, our findings show the potential to expand the scope of research on this subject. We suggest that it is necessary to observe and consider long-term $\mathrm{PM}_{2.5}$ microbial activity and toxicity under non-serious air pollution levels to allow for more rigorous analyses of related $\mathrm{PM}_{2.5}$ biological components.

\section{ACKNOWLEDGMENTS}

This research was found by the National Science Foundation of China (Grant no. 41775135) and the Beijing Natural Science Foundation (Grant no. 8172045). 


\section{SUPPLEMENTARY MATERIAL}

Supplementary data associated with this article can be found in the online version at http://www.aaqr.org.

\section{REFERENCES}

Abd Aziz, A., Lee, K., Park, B., Park, H., Park, K., Choi, I.G. and Chang, I.S. (2018). Comparative study of the airborne microbial communities and their functional composition in fine particulate matter $\left(\mathrm{PM}_{2.5}\right)$ under non-extreme and extreme $\mathrm{PM}_{2.5}$ conditions. Atmos. Environ. 194: 82-92.

Bi, W., Chen, K., Xiao, Z., Tang, M., Zheng, N., Yang, N., Gao, J., Li, Y., Kong, J. and Xu, H. (2019). Health benefit assessment of China's national action plan on air pollution in the Beijing-Tianjin-Hebei area. Aerosol Air Qual. Res. 19: 383-389.

Brook, I. (2009). The role of beta-lactamase-producingbacteria in mixed infections. BMC Infect. Dis. 9: 202

Cao, C., Jiang, W., Wang, B., Fang, J., Lang, J., Tian, G., Jiang, J. and Zhu, T.F. (2014). Inhalable microorganisms in Beijing's $\mathrm{PM}_{2.5}$ and $\mathrm{PM}_{10}$ pollutants during a severe smog event. Environ. Sci. Technol. 48: 1499-1507.

Chan, C.K. and Yao, X. (2008). Air pollution in mega cities in China. Atmos. Environ. 42: 1-42.

Christner, B.C., Cai, R., Morris, C.E., McCarter, K.S., Foreman, C.M., Skidmore, M.L., Montross, S.N. and Sands, D.C. (2008). Geographic, seasonal, and precipitation chemistry influence on the abundance and activity of biological ice nucleators in rain and snow. Proc. Natl. Acad. Sci. U.S.A. 105: 18854-18859.

Després, V., Huffman, J.A., Burrows, S.M., Hoose, C., Safatov, A., Buryak, G., Fröhlich-Nowoisky, J., Elbert, W., Andreae, M., Pöschl, U. and Jaenicke, R. (2012). Primary biological aerosol particles in the atmosphere: A review. Tellus Ser. B 64: 15598.

Dong, L., Qi, J., Shao, C., Zhong, X., Gao, D., Cao, W., Gao, J., Bai, R., Long, G. and Chu, C. (2016). Concentration and size distribution of total airborne microbes in hazy and foggy weather. Sci. Total Environ. 541: 1011-1018.

Du, P., Du, R., Lu, Z., Ren, W. and Fu, P. (2018a). Variation of bacterial and fungal community structures in $\mathrm{PM}_{2.5}$ collected during the 2014 apec summit periods. Aerosol Air Qual. Res. 18: 444-455.

Du, P., Du, R., Ren, W., Lu, Z. and Fu, P. (2018b). Seasonal variation characteristic of inhalable microbial communities in $\mathrm{PM}_{2.5}$ in Beijing city, China. Sci. Total Environ. 610-611: 308-315.

Du, P., Du, R., Ren, W., Lu, Z., Zhang, Y. and Fu, P. (2018c). Variations of bacteria and fungi in $\mathrm{PM}_{2.5}$ in Beijing, China. Atmos. Environ. 172: 55-64.

Duan, F.K., He, K.B., Ma, Y.L., Yang, F.M., Yu, X.C., Cadle, S.H., Chan, T. and Mulawa, P.A. (2006). Concentration and chemical characteristics of $\mathrm{PM}_{2.5}$ in Beijing, China: 2001-2002. Sci. Total Environ. 355: 264-275.

Fan, C., Li, Y., Liu, P., Mu, F., Xie, Z., Lu, R., Qi, Y.,
Wang, B. and Jin, C. (2019). Characteristics of airborne opportunistic pathogenic bacteria during autumn and winter in Xi'an, China. Sci. Total Environ. 672: 834845.

Franklin, M., Zeka, A. and Schwartz, J. (2007). Association between $\mathrm{PM}_{2.5}$ and all-cause and specificcause mortality in 27 US communities. J. Exposure Sci. Environ. Epidemiol. 17: 279-287.

Gao, J., Woodward, A., Vardoulakis, S., Kovats, S., Wilkinson, P., Li, L., Xu, L., Li, J., Yang, J., Li, J., Cao, L., Liu, X., Wu, H. and Liu, Q. (2017a). Haze, public health and mitigation measures in China: A review of the current evidence for further policy response. Sci. Total Environ. 578: 148-157.

Gao, J.F., Fan, X.Y., Li, H.Y. and Pan, K.L. (2017b). Airborne bacterial communities of $\mathrm{PM}_{2.5}$ in BeijingTianjin-Hebei megalopolis, China as revealed by Illumina MiSeq sequencing: A case study. Aerosol Air Qual. Res. 17: 788-798.

Gao, M., Jia, R., Qiu, T., Han, M., Song, Y. and Wang, X. (2015). Seasonal size distribution of airborne culturable bacteria and fungi and preliminary estimation of their deposition in human lungs during non-haze and haze days. Atmos. Environ. 118: 203-210.

Gao, M., Yan, X., Qiu, T., Han, M. and Wang, X. (2016). Variation of correlations between factors and culturable airborne bacteria and fungi. Atmos. Environ. 128: 10-19.

Green, V.S., Stott, D.E. and Diack, M. (2006). Assay for fluorescein diacetate hydrolytic activity: Optimization for soil samples. Soil Biol. Biochem. 38: 693-701.

Guan, T., Yao, M., Wang, J., Fang, Y., Hu, S., Wang, Y., Dutta, A., Yang, J., Wu, Y., Hu, M. and Zhu, T. (2014). Airborne endotoxin in fine particulate matter in Beijing. Atmos. Environ. 97: 35-42.

Jaenicke, R. (2005). Abundance of cellular material and proteins in the atmosphere. Science 308: 73.

Jones, A.M. and Harrison, R.M. (2004). The effects of meteorological factors on atmospheric bioaerosol concentrations-A review. Sci. Total Environ. 326: 151-180.

Kozich, J.J., Westcott, S.L., Baxter, N.T., Highlander, S.K. and Schloss, P.D. (2013). Development of a dual-index sequencing strategy and curation pipeline for analyzing amplicon sequence data on the MiSeq Illumina sequencing platform. Appl. Environ. Microbiol. 79: 5112-5120.

Kurkela, T. (1997). The number of Cladosporium conidia in the air in different weather conditions. Grana 36: 54 61.

Lacey, J. and Dutkiewicz, J. (1994). Bioaerosols and occupational lung-disease. J. Aerosol Sci. 25: 1371-1404.

Lang, J., Zhang, Y., Zhou, Y., Cheng, S., Chen, D., Guo, X., Chen, S., Li, X., Xing, X. and Wang, H. (2017). Trends of $\mathrm{PM}_{2.5}$ and chemical composition in Beijing, 2000-2015. Aerosol Air Qual. Res. 17: 412-425.

Li, J., Li, M., Shen, F., Zou, Z., Yao, M. and Wu, C.Y. (2013). Characterization of biological aerosol exposure risks from automobile air conditioning system. Environ. Sci. Technol. 47: 10660-10666.

Li, M., Qi, J., Zhang, H., Huang, S., Li, L. and Gao, D. 
(2011). Concentration and size distribution of bioaerosols in an outdoor environment in the Qingdao coastal region. Sci. Total Environ. 409: 3812-3819.

Li, Y., Fu, H., Wang, W., Liu, J., Meng, Q. and Wang, W. (2015). Characteristics of bacterial and fungal aerosols during the autumn haze days in Xi'an, China. Atmos. Environ. 122: 439-447.

Li, Y., Lu, R., Li, W., Xie, Z. and Song, Y. (2017). Concentrations and size distributions of viable bioaerosols under various weather conditions in a typical semi-arid city of Northwest China. J. Aerosol Sci. 106: 83-92.

Meng, X.B., Li, M.Z., Li, H.T., Gao, D.M. and Qi, J.H. (2016). Microbial activity in bioaerosols in winter at the coastal region of Qingdao. Huanjing Kexue 37: 41474155.

Polymenakou, P.N. (2012). Atmosphere: A source of pathogenic or beneficial microbes? Atmosphere 3: 87102.

Qi, J., Zhong, X., Shao, Q., Gao, D., Wu, L., Huang, L. and Ye, Y. (2015). Microbial activity levels in atmospheric bioaerosols in Qingdao. Aerobiologia 31: 353-365.

Ren, W., Du, R., Du, P. and Zhang, S. (2018). Microbial activity in atmospheric $\mathrm{PM}_{2.5}$. Microbiol. China 45: 2071-2081.

Shi, L., Zanobetti, A., Kloog, I., Coull, B.A., Koutrakis, P., Melly, S.J. and Schwartz, J.D. (2016). Low-concentration $\mathrm{PM}_{2.5}$ and mortality: Estimating acute and chronic effects in a population-based study. Environ. Health Perspect. 124: 46-52.

Slonczewski, J.L. and Foster, J.W. (2013). Microbiology: An evolving science: Third international student edition. WW Norton \& Company.

Smets, W., Moretti, S., Denys, S. and Lebeer, S. (2016). Airborne bacteria in the atmosphere: Presence, purpose, and potential. Atmos. Environ. 139: 214-221.

Tang, J.W. (2009). The effect of environmental parameters on the survival of airborne infectious agents. J. R. Soc. Interface 6: S737-S746.

Tarigan, Y.G., Chen, R.Y., Lin, H.C., Jung, C.Y., Kallawicha, K., Chang, T.P., Hung, P.C., Chen, C.Y. and Chao, H.J. (2017). Fungal bioaerosol exposure and its effects on the health of mushroom and vegetable farm workers in Taiwan. Aerosol Air Qual. Res. 17: 2064- 2075.

Wang, Q., Garrity, G.M., Tiedje, J.M. and Cole, J.R. (2007). Naive Bayesian classifier for rapid assignment of rRNA sequences into the new bacterial taxonomy.
Appl. Environ. Microbiol. 73: 5261-5267.

Wei, K., Zou, Z., Zheng, Y., Li, J., Shen, F., Wu, C.Y., Wu, Y., Hu, M. and Yao, M. (2016). Ambient bioaerosol particle dynamics observed during haze and sunny days in Beijing. Sci. Total Environ. 550: 751-759.

Whyte, W., Hodgson, R. and Tinkler, J. (1982). The importance of airborne bacterial contamination of wonds. J. Hosp. Infect. 3: 123-135.

Xie, Z., Li, Y., Lu, R., Li, W., Fan, C., Liu, P., Wang, J. and Wang, W. (2018). Characteristics of total airborne microbes at various air quality levels. J. Aerosol Sci. 116: 57-65.

Xiu, G., Wu, X., Wang, L., Chen, Y., Yu, Y., Xu, F. and Wu, L. (2015). Characterization of particulate matter, ions and $\mathrm{OC} / \mathrm{EC}$ in a museum in Shanghai, China. Aerosol Air Qual. Res. 15: 1240-1250.

Xu, C., Wei, M., Chen, J., Wang, X., Zhu, C., Li, J., Zheng, L., Sui, G., Li, W., Wang, W., Zhang, Q. and Mellouki, A. (2017). Bacterial characterization in ambient submicron particles during severe haze episodes at Ji'nan, China. Sci. Total Environ. 580: 188-196.

Xu, W.Z., Chen, H., Li, D.H., Zhao, F.S. and Yang, Y. (2013). A case study of aerosol characteristics during a haze episode over Beijing, In 2013 international symposium on environmental science and technology, Quan, X. (Ed.), Elsevier Science Bv, Amsterdam, pp. 404-411.

Zhang, Y., Huang, W., Cai, T., Fang, D., Wang, Y., Song, J., Hu, M. and Zhang, Y. (2016). Concentrations and chemical compositions of fine particles $\left(\mathrm{PM}_{2.5}\right)$ during haze and non-haze days in Beijing. Atmos. Res. 174175: 62-69.

Zhao, M., Wang, S., Tan, J., Hua, Y., Wu, D. and Hao, J. (2016). Variation of urban atmospheric ammonia pollution and its relation with $\mathrm{PM}_{2.5}$ chemical property in winter of Beijing, China. Aerosol Air Qual. Res. 16: 13781389

Zhong, X., Qi, J., Li, H., Dong, L. and Gao, D. (2016). Seasonal distribution of microbial activity in bioaerosols in the outdoor environment of the Qingdao coastal region. Atmos. Environ. 140: 506-513.

Received for review, May 18, 2019

Revised, July 11, 2019

Accepted, July 16, 2019 